\title{
Longstanding Complicated Wrist Swelling: A Typical Presentation of Primary Tuberculosis a Case Report and Mini Review
}

\author{
Reem Hamdy A Mohammed ${ }^{1 *}$, Raghda Mahmoud Farghaly ${ }^{2}$, Andrea Di Matteo ${ }^{3}$ \\ ${ }^{1}$ Professor of Rheumatology and Rehabilitation, Department of Rheumatology and Rehabilitation- School of Medicine- Cairo University. \\ ${ }^{2}$ Assistant Lecturer of Rheumatology and rehabilitation, Department of Rheumatology and Rehabilitation- School of Medicine- Cairo University. \\ ${ }^{3}$ Rheumatology Department, Università Politecnica delle Marche, “Carlo Urbani” Hospital, Iesi, Ancona, Italy.
}

*Corresponding Author: Reem Hamdy A Mohammed, Professor of Rheumatology and Rehabilitation, Department of Rheumatology and Rehabilitation- School of Medicine- Cairo University.

Received date: June 17, 2021; Accepted date: August 09, 2021; Published date: August 18, 2021

Citation: RHA Mohammed, Raghda M Farghaly, Andrea D Matteo. (2021) Longstanding Complicated Wrist Swelling: A Typical Presentation of Primary Tuberculosis a case report and mini review. International Journal of Clinical Case Reports and Reviews. 8(2); DOI:10.31579/2690-4861/147

Copyright: @ 2021 Reem Hamdy A Mohammed, This is an open-access article distributed under the terms of the Creative Commons Attribution License, which permits unrestricted use, distribution, and reproduction in any medium, provided the original author and source are credited.

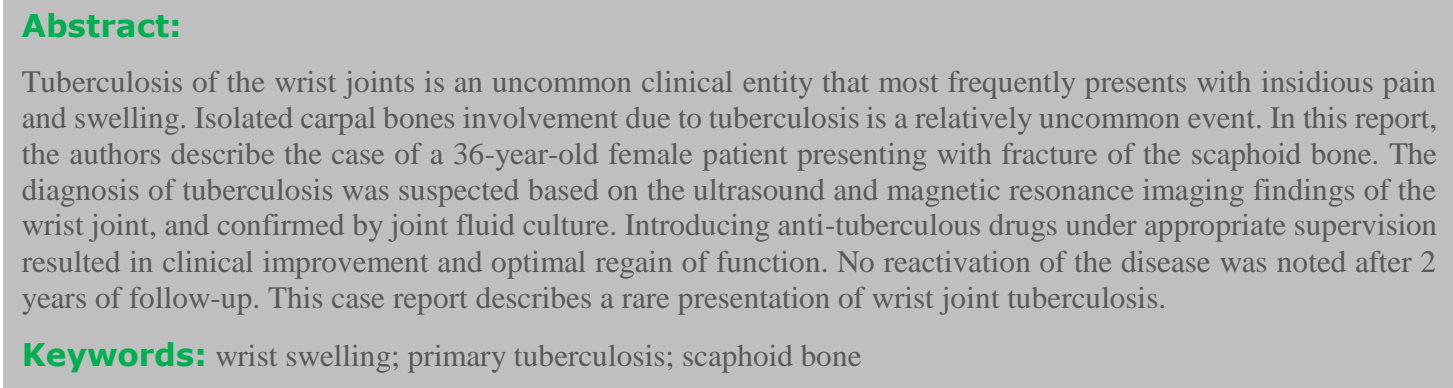

\section{Introduction:}

Primary (isolated) tuberculosis (TB) of the hand and wrist has been rarely reported in the literature, representing $<1 \%$ of extra-pulmonary manifestations of the disease [1-3].

Symptoms vary depending on the specific wrist or hand joint which is affected by TB. The involvement of the wrist typically begins in the scapholunate joint. The diagnosis of wrist tuberculosis is often late; when discovered at an early stage, a well-followed medical treatment is usually enough to provide full healing.

\section{Case Report:}

The case presented is an Egyptian illiterate 36-year-old housewife patient from a low income family, married with no off springs and has no special habits of medical importance was referred to the outpatient clinic of rheumatology and rehabilitation complaining of painless, swelling of the left wrist of 1 year and 6 months duration.

Previous medical history: The condition started with a painless of the left wrist, of gradual onset and progressive course, not associated with morning stiffness or local redness. The patient sought medical advice at orthopedic clinic at $\mathrm{Al}$ Kasr Alainy Hospital, where aspiration of one of the swellings and investigations were done.

\section{Clinical presentation and investigations at encounter:}

The patient was referred to rheumatology and rehabilitation outpatient clinic. On examination there was a boggy synovial thickening with multilocular swelling on the dorsal aspect of the left wrist, with limited dorsiflexion and extension, no local redness or hotness. No evidence of arthritis or limited range of motion in any of the other joints of the upper or lower limbs. Examination of other body systems revealed no abnormality detected. Review of the past history for the present illness, the patient gave history of loss of weight despite of good appetite, vague history of unmeasured fever not associated with skin rash, rigors or excessive night sweats and not associated with an evident source of infection. The patient did not report any chest symptoms. There was no history of subcutaneous nodules, no other joint or musculoskeletal complaints of significance. There was no history of alopecia, oral ulcers, genital ulcers, malar rash, photosensitivity or Raynaud's phenomenon, no history of DVT, TIAs, stroke or any vascular event, no history of cough, hemoptysis, or dyspnea. No history of tingling, hypothesia or muscle 
weakness, no history of chronic diarrhea or change of bowel habits or GIT bleeding. No history of bleeding from body orifices.

Laboratory investigations revealed normal complete blood count, normal chemistry and with normal ranges for inflammatory biomarkers (erythrocyte sedimentation rate and $\mathrm{C}$ reactive protein), tuberculin test was weak positive.

Plain $\mathrm{x}$ ray of the wrist revealed an old fracture of Lt distal forearm with avascular necrosis of the scaphoid bone. Figure $1(\mathrm{a} \& \mathrm{~b})$

Musculoskeletal US revealed significant villous like synovial thickening with power Doppler signal indicating increased vascularity. Scaphoidectomy, wire fixation and synovectomy of extensor compartment were done at the orthopedic clinic. Figure 2.
Computerized tomography scan (CT scan) of the Lt wrist revealed an old non-united fracture of the left scaphoid bone waist with gapped sclerosed fracture ends and adjacent tiny bone chips. Scapholunate dissociation with widening intervening spaces. Anterior tilt of the lunate bone denoting ventral intercalated segmental instability. Secondary osteoarthritic changes of radio-carpal joint with marginal osteophytosis of articular surface. Multi-locular cystic lesion is seen along dorsum of $\mathrm{Lt}$ wrist measuring $3.2 \times 2.5 \mathrm{~cm}$, likely extensor tendon tenosynovitis. Figure 3 (a \&b)

Magnetic resonance imaging (MRI) of the left wrist revealed normal appearance of the proximal and distal carpal bones with no evidence of avascular necrosis (AVN). No fluid collection was seen. Figure 4

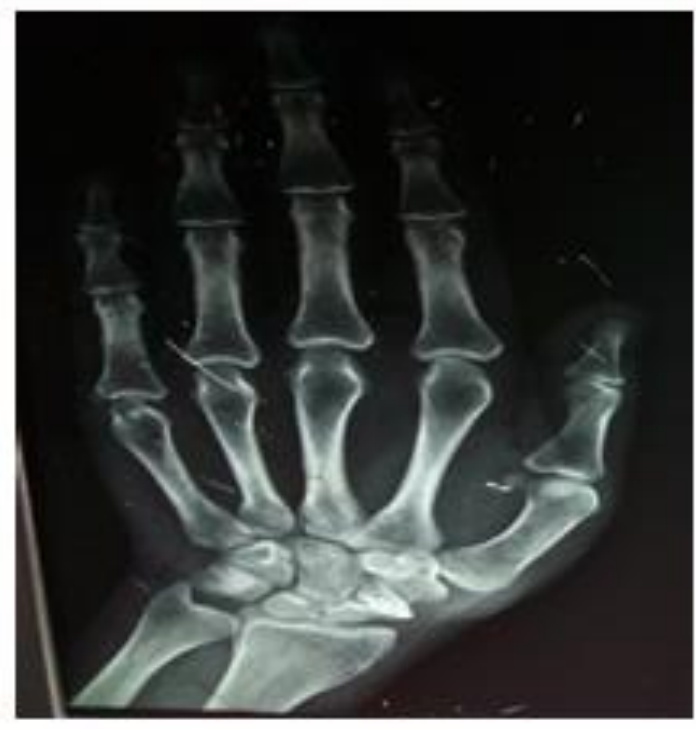

Figure 1(a)

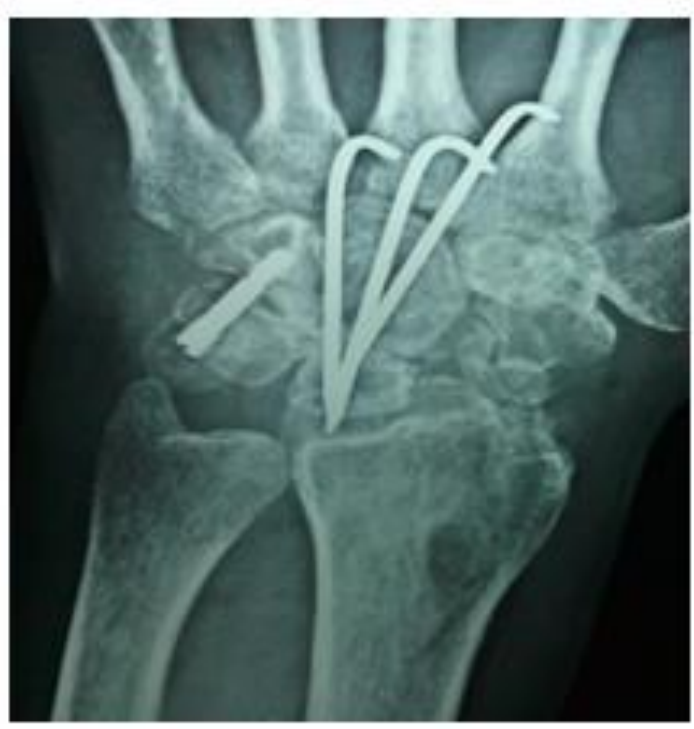

Figure 1(b)

Figure 1: Plain radiography of the left wrist joint showing avascular necrosis of the scaphoid bone, large cystic lesions in distal radius, an old fracture of Lt distal forearm that was later surgically treated by wire fixation ( $a \& b$ respectively).

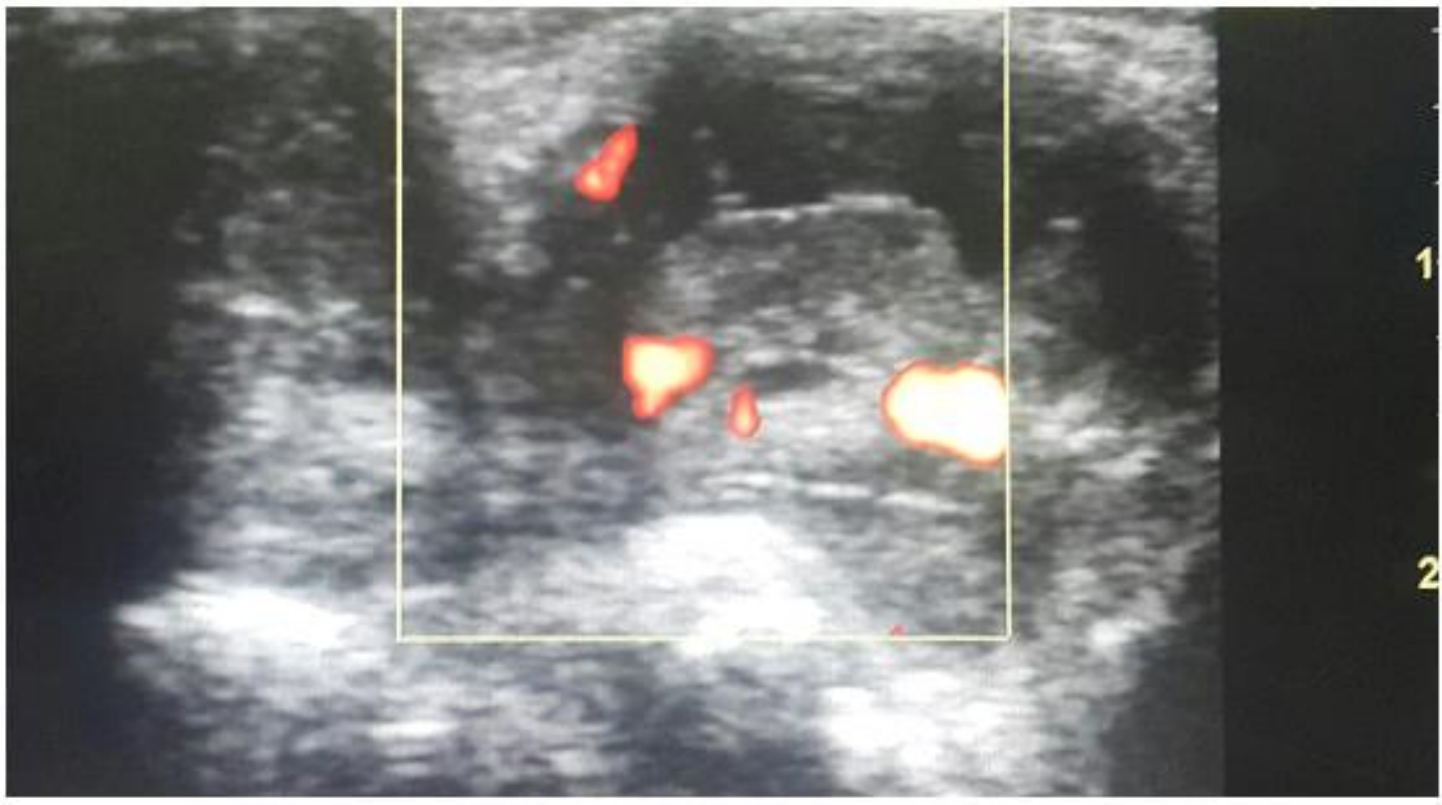

Figure 2: Ultrasound examination of the left wrist using an 8-13 $\mathrm{MHz}$ linear transducer significant synovial thickening with increased vascularity on doppler examination with multiple locular fluid filled compartments and floating hyperechoic shadows. 


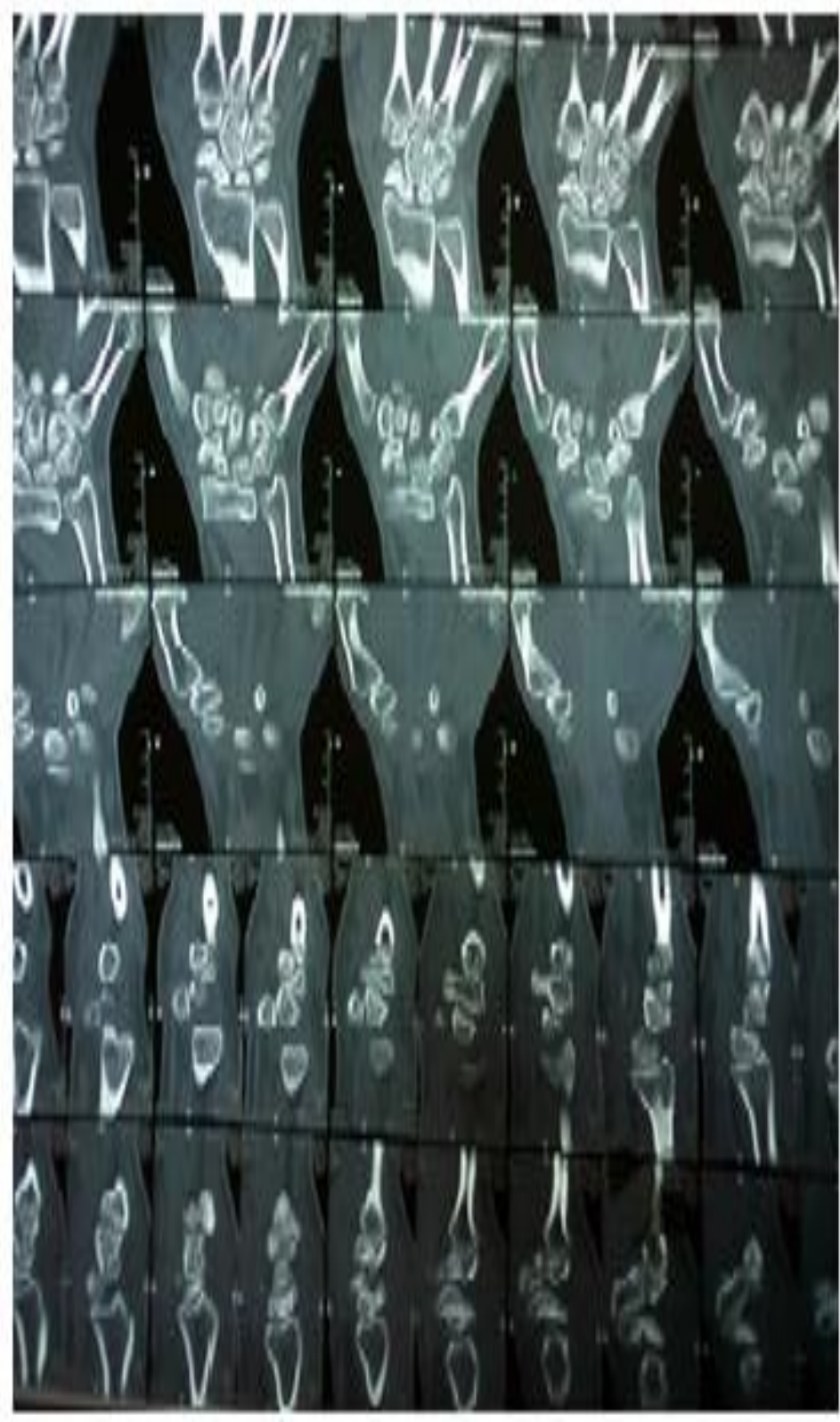

Figure 3 (a): CT of the left wrist

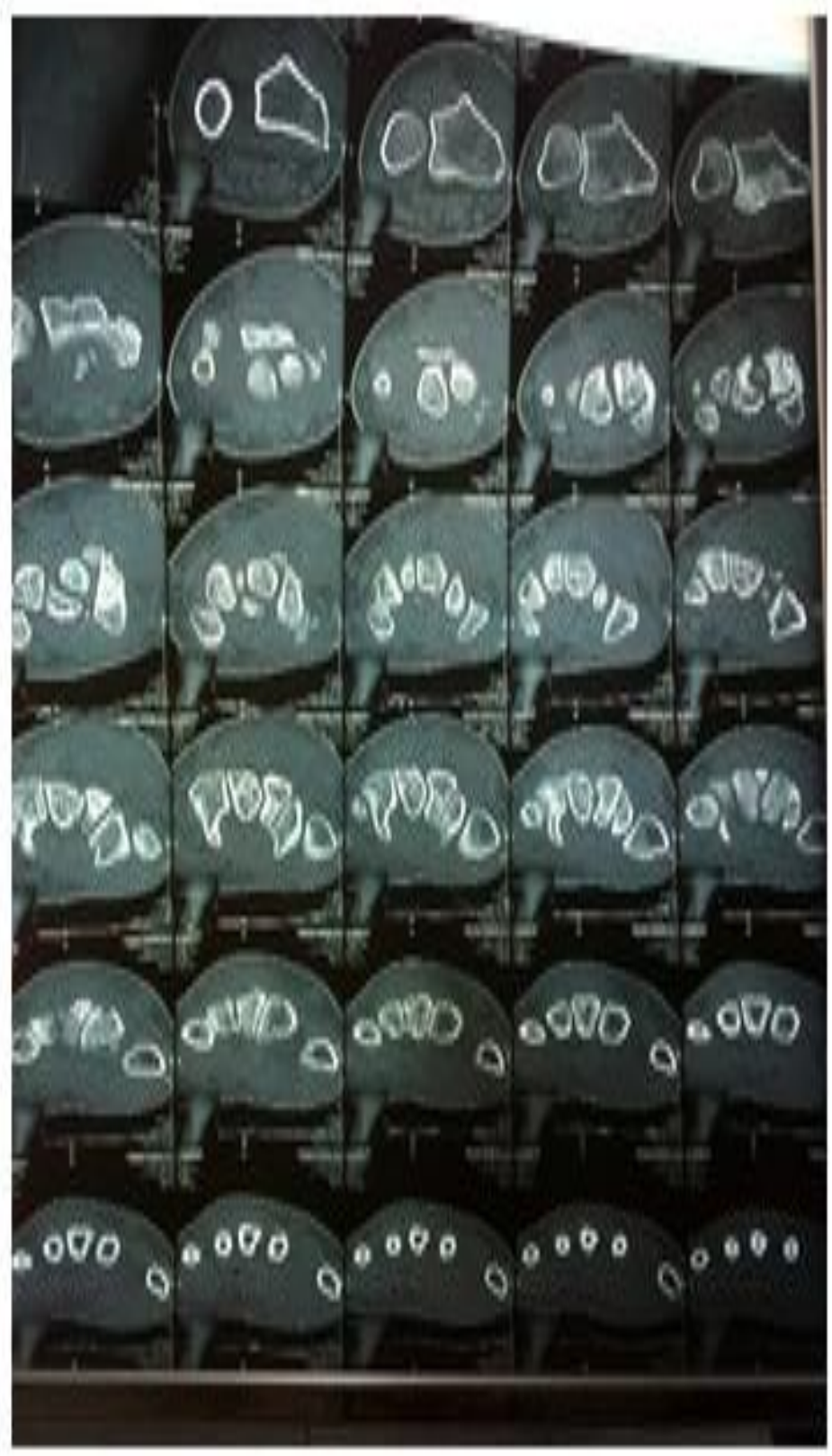

Figure 3(b): CT of the left wrist.

Figure 3 (a \& b): Computerized tomography scan (CT scan) of the Lt wrist revealed an old non-united fracture of the left scaphoid bone waist with gapped sclerosed fracture ends and adjacent tiny bone chips. Scapholunate dissociation with widening intervening spaces. Anterior tilt of the lunate bone denoting ventral intercalated segmental instability. Secondary osteo-arthritic changes of radio-carpal joint with marginal osteophytosis of articular surface. Multi-locular cystic lesion is seen along dorsum of Lt wrist measuring $3.2 \times 2.5 \mathrm{~cm}$, likely extensor tendon tenosynovitis. 


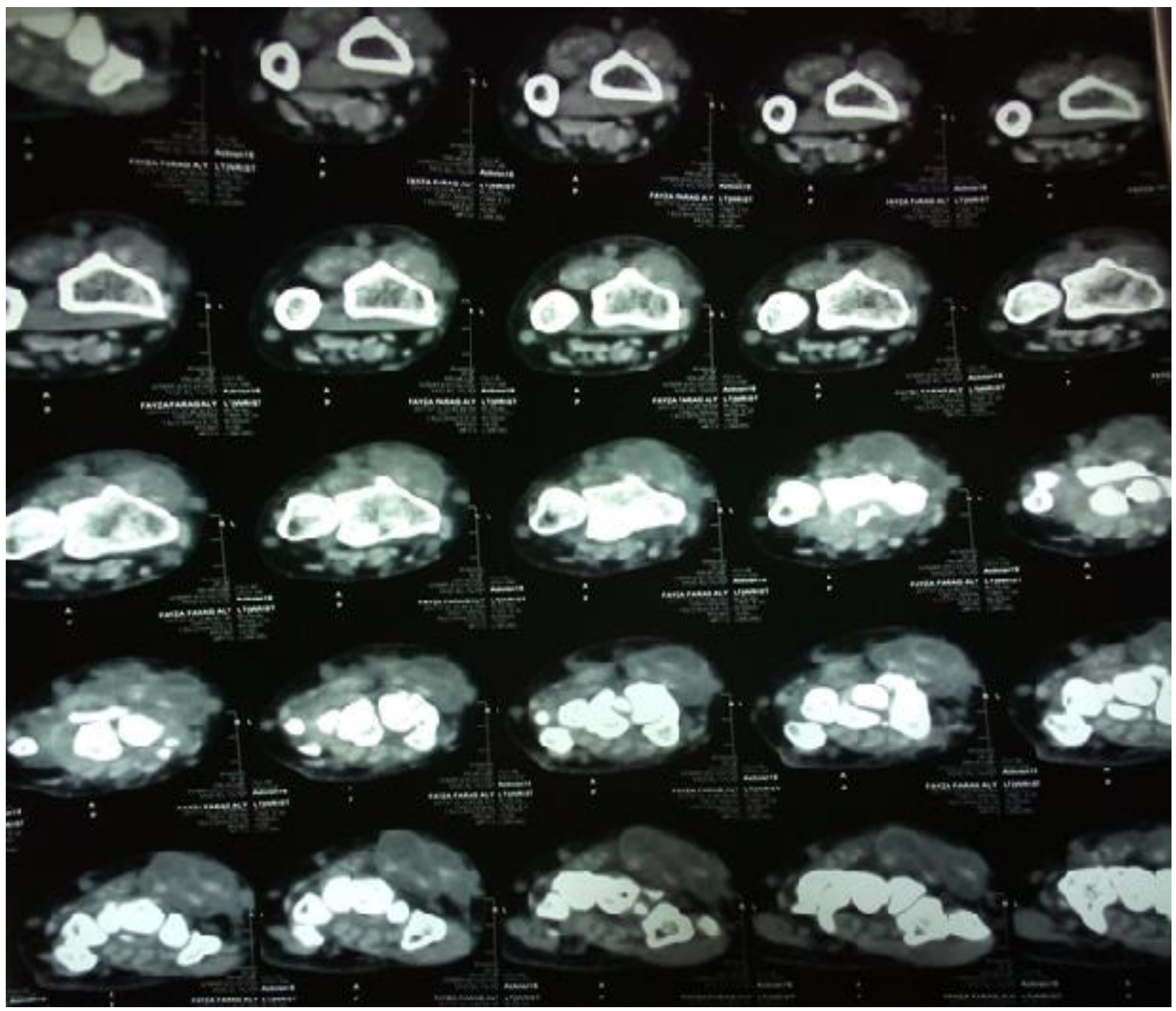

Figure 4: MRI of the left wrist using different pulse sequences in different planes Scaphoid fracture is seen. Normal appearance of the proximal and distal carpal bones with no evidence of avascular necrosis (AVN). No fluid collection is seen.

\section{Pathology, microscopy and histopathological} examination of the excised synovial tissue:

Gross pathological examination revealed multiple irregular fibrofatty tissue pieces, collectively measuring $6 \times 6 \mathrm{~cm}$ with rubbery tan cut section. Multiple irregular tan pink tissue pieces, collectively measuring $2 \times 2 \mathrm{~cm}$ totally submitted.

Microscopic tissue examination revealed synovial tissue showing multiple scattered granulomatous tubercles formed of epithelioid cells, multinucleated giant cells and lymphocytes. Moderate fibrosing reaction. Minimal caseation. Fibrinous material. Positive culture for tuberculosis (T.B). Findings consistent with tuberculous infection with tuberculous synovitis.

\section{Treatment:}

The patient was started on anti-tuberculous therapy together with radical synovectomy showing a good response to treatment.

\section{Conclusion:}

In the presented case report authors present a rare case of persistent wrist swelling in a middle-aged female that was diagnosed radiologically and histo-pathologically as a case of primary tuberculosis of the wrist joint. Tuberculosis of wrist joint though uncommon should be considered amongst the differentials in any atypical presentation with wrist pain and/or swelling of the wrist joint with or without significant history of concomitant or past tuberculous infection with special consideration of patient related socioeconomic and educational factors.

\section{References:}

1. Mihalko MJ, Martinez SF. Canale ST, Beaty JH. (2013) Tuberculosis and other unusual infections. Campbell's Operative Orthopedics 12th ed.Mosby, Philadelphia. 773-786.

2. Sbai MA, Benzarti S, Sahli H, et al. (2015) Osteoarticular tuberculosis dactylitis: four cases. Int J Mycobacteriol. 4:250254 . 
3. Ozçelik IB, Aydin A, Sezer I, et al. (2006) Treatment algorithm in synovial tuberculosis of the hand and wrist: a report of three cases. Acta Orthop Traumatol Turc. 40:255-259.

4. Prakash J, Mehtani A. (2015) Isolated tuberculosis of scaphoid in the skeletally immature: a rare cause of chronic wrist pain. BMJ Case Rep.

5. Soman SM, Patel BN, Shah PD. (2015) Persistent posttraumatic wrist paintuberculosis infection should be in the differential diagnosis. A rare case report. J Orthop Case Rep. 5:17-20.

6. Bayram S, Ers, en A, Altan M, et al. (2016) Tuberculosis tenosynovitis with multiple rice bodies of the flexor tendons in the wrist: a case report. Int J Surg Case Rep. 27:129-132.

7. Güner MD, Bektas, U, Akmes, e R. (2015) Wrist tenosynovitis due to Mycobacterium bovis infection: case series and review of the literature. Plast Reconstr Surg Glob Open.
8. Kotwal PP, Khan SA. (2009) Tuberculosis of the hand: clinical presentation and functional outcome in 32 patients. J Bone Joint Surg Br. 91:1054-1057.

9. Dlimi F, Bellarbi S, Mahfoud M, et al. (2011) Tuberculosis of the hand and wrist: different aspects of 30 cases. Chir Main. 30:198-204.

10. Vigler M, Mulett H, Hausman MR. Chronic Mycobacterium infection of first dorsal web space after accidental Bacilli Calmette-Guérin injection in a health worker: case report. J Hand Surg Am. 33:1621-1624.

11. Visuthikosol V, Kruavit A, Nitiyanant P, et al. (1996) Tuberculous infection of the hand and wrist. Ann Plast Surg. 37:55-59.

12. Vinil S, Mangesh D, Harshal T P. (2018) Tuberculosis of Wrist Joint in Young Female: A Very Rare Case. JOJ Case Stud. 6(2).
This work is licensed under Creative Commons Attribution 4.0 License

To Submit Your Article Click Here: Submit Manuscript

DOI: $10.31579 / 2690-4861 / 146$
Ready to submit your research? Choose Auctores and benefit from:

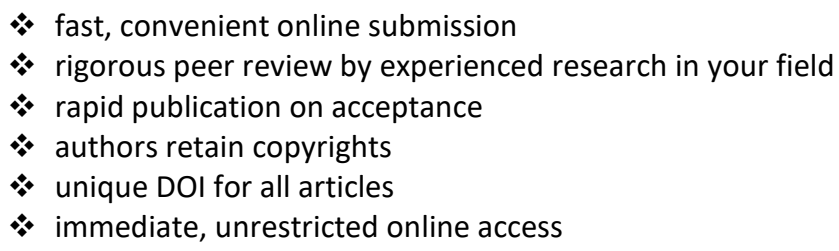

At Auctores, research is always in progress.

Learn more www.auctoresonline.org/journals/international-journal-ofclinical-case-reports-and-reviews 